\title{
ANÁLISE DE ARREMESSOS DE CONTRA-ATAQUE NO CAMPEONATO MUNDIAL DE HANDEBOL MASCULINO SUÉCIA 2011
}

DOI: 105902/0102830814667

Data de envio: 01/07/2015

Data de aceite: 10/11/2015

Roberto Andaki Junior

Universidade Federal de Viçosa

robertoandakijr@gmail.com

Alynne Christian Ribeiro Andaki Universidade Federal do Triângulo Mineiro alynneandaki@yahoo.com.br

Edmar Lacerda Mendes

Universidade Federal do Triângulo Mineiro edmar@ef.uftm.edu.br

\section{José Geraldo Do Carmo Salles \\ Universidade Federal de Viçosa gege_handebol@yahoo.com.br}

RESUMO: O objeto do estudo foi verificar o número e eficácia de arremessos de contra-ataque nos resultados de vitória, derrota ou empate dos participantes do Campeonato Mundial Masculino de Handebol, Suécia 2011. A amostra foi composta de 98 jogos da competição. Foram analisados os números de gols de contra-ataques, total de arremessos e a eficácia nesta situação. ANOVA oneway seguida pelo teste post hoc de Tukey HSB ou Welch apontou que equipes vitoriosas apresentaram maior número de arremessos, eficácia de arremessos e gols na situação de contra-ataque em relação a equipes derrotadas. Gols provenientes de contra-ataque são mais frequentes entre equipes vitoriosas, ressaltando a sua importância tática para treinadores e atletas nas respectivas ações de elaboração e execução de treinamento.

Palavras-chave: Handebol. Contra-ataque. Campeonato mundial. 


\section{INTRODUÇÃO}

O método da observação direta, o registro e a análise das ações técnicas e táticas tem um papel cada vez mais relevante no crescimento e desenvolvimento do esporte coletivo. A estatística é cada vez mais presente antes, durante, e depois do evento esportivo, e revela dados que identificam falhas e êxitos de um atleta, de uma equipe ou, ainda, fornece o conhecimento do nível da competição (ANDAKI JUNIOR et al., 2009).

O handebol se caracteriza pela constante ação de atacar e defender durante o ciclo do jogo, marca que é retratada pela busca do gol e a luta pela posse da bola em todo momento (GARCÍA, 2000), e esse dinamismo que parece tornar o esporte interessante aos praticantes e aos espectadores.

Segundo Hernández (1998), o handebol é um esporte sociomotor de cooperação e oposição, desenvolvido em um espaço padronizado e de utilização comum aos participantes, intervindo simultaneamente sobre a bola e cujos objetivos antagônicos são: para os atacantes fazer com que a bola seja introduzida na meta, e para os defensores, evitar que isso aconteça. A dinâmica do jogo proporciona a alteração do objeto.

Román (2007) ao realizar uma revisão sobre a evolução do jogo de handebol no início do século XXI destaca o aumento na velocidade do jogo como um dos componentes mais importantes tanto no masculino como no feminino. Por exemplo, com a mudança na regra sobre o tiro de saída (contra-gol) após conversão de um gol em 1997. Permitiu a equipe adversária permanecer nas duas metades da quadra, impôs aos técnicos e jogadores a necessidade de (re)pensar ações táticas ofensivas e defensivas. Não é somente o aumento do jogo em contra-ataque e contra-gol que influência diretamente o jogo tático, trata-se de uma filosofia de atuação que evoluciona o jogo para uma pressão psicológica de velocidade nas ações.

O contra-ataque segundo Ramirez (2010) é a fase que ocorre depois da defesa e antes da organização do ataque, que se inicia quando a equipe consegue 
a posse de bola proveniente de um erro do adversário ou com um arremesso defendido pelo goleiro. O contra-ataque tem como objetivo a transição rápida da bola com finalidade de obter uma situação vantajosa para o lançamento de uma forma facilitada (GUTIÉRREZ, 1999).

Segundo Delgado (2004) é a ação individual ou coletiva pelo qual a equipe tenta rapidamente fazer o gol depois de um êxito defensivo. Ainda sobre o contraataque Salles (2001) acrescenta que o contra-ataque pode ser executado de forma direta ou indireta. Contra-ataque de forma direta é realizado por meio de roubo de bola, lançamento do goleiro e violação das regras quando não ocorre mais de um passe ou, antes de finalizado o lançamento. Por sua vez, o contra-ataque de forma indireta pode ser realizado por meio de câmbio (quando o goleiro passa a responsabilidade para outro jogador realizar o lançamento) e o sustentado (que é realizado em forma de bloco com passes rápidos). Vários autores (GUTIÉRREZ, 1999; ROGULJ, SRHOJ e SRHOJ, 2004; ANDAKI JUNIOR et al. 2009; DA SILVA et al. 2009; SÁEZ, ROLDÁN e FEU, 2009; GARCÍA et al., 2010) valorizam o contra-ataque como um dos fatores determinantes ao sucesso das equipes em seus estudos.

Este estudo objetivou verificar o número e eficácia das ações de arremessos de contra-ataque nos resultados de vitória, derrota ou empate dos participantes do campeonato Mundial Masculino de Handebol, Suécia 2011.

\section{METODOLOGIA}

\section{Amostra}

Foram analisados todos os 98 jogos realizados no Campeonato Mundial Masculino de Handebol, Suécia 2011. Participaram deste evento 24 equipes, divididas em quatro chaves com seis equipes. As equipes jogaram entre si dentro das chaves, classificando-se as três primeiras para segunda fase. A segunda fase foi realizada em duas chaves de seis equipes, classificando-se as duas melhores seleções de cada chave para as semifinais e, consequentemente, depois para 
disputa dos primeiros lugares. . O Campeonato Mundial Masculino de Handebol é realizado a cada dois anos e é considerado o maior torneio de seleções na modalidade, contando com equipes e atletas de todos os continentes.

\section{Procedimentos}

O número e eficácia de arremessos de contra-ataques (gols ou não) e o percentual dos gols sobre o resultado final (PGCA) das partidas (vitória, derrota ou empate) foram recolhidos do site da Federação Internacional de Handebol (IHF).

\section{Análise estatística}

A homogeneidade das variâncias foi checada pelo teste de Levene e, quando violada a pressuposição, o ajustamento de Welch foi utilizado. ANOVA OneWay com teste post hoc de Tukey HSB (igualdade das variâncias assumida) ou Games-Howell (igualdade das variâncias não assumida) foram utilizadas para testar diferenças entre as variáveis do estudo nas condições de vitória, derrota ou empate. O tamanho do efeito ( $\eta 2$ ) foi calculado para estimar a magnitude das diferenças e classificados como pequeno $=0,01$, médio $=0,06$ e grande $=0,14$ (COHEN, 1988). O valor de $p<0,05$ foi estabelecido e para as análises foi utilizado o programa Statistical Package for the Social Sciences (IBM SPSS Statistics 19.0 versão para Windows).

\section{RESULTADOS}

As equipes participantes do Campeonato Mundial Masculino de Handebol, Suécia 2011 apresentaram 27,52 $\pm 5,97$ gols por partida, com 4,85 $\pm 2,89$ gols de contra-ataques dos 6,5 $\pm 3,50$ arremessos realizados, o que representa eficácia de $72,28 \pm 23,55 \%$, Tabela 1 . Os gols de contra-ataque foram responsáveis por $23,27 \pm 11,17 \%$ do total de gols das partidas. 


\begin{tabular}{lcc}
\hline & Média & Desvio padrão \\
\hline Gols & 27,52 & 5,97
\end{tabular}

Contra-ataque

\begin{tabular}{lcc} 
Arremessos & 6,50 & 3,50 \\
Gols & 4,85 & 2,89 \\
Eficácia (\%) & 72,28 & 23,55 \\
PGCA (\%) & 23,27 & 11,17 \\
\hline
\end{tabular}

PGCA - Percentual dos gols de contra-ataque no total de gols.

Tabela 1. Distribuição do número de gols e eficácia do contra-ataque das equipes participantes do Campeonato Mundial Masculino de Handebol, Suécia 2011

Equipes vitoriosas apresentaram maior número de gols $[F(2,195)=49,446$; $0,001 ; \eta 2=0,34]$, gols de contra-ataque $[F(2,195)=19,488 ; 0,001 ; \eta 2=0,17]$ e arremessos realizados de contra-ataque $[F(2,195)=13,541 ; 0,001 ; \eta 2=0,12] \mathrm{em}$ relação às situações de derrota e empate, Tabela 2. Por sua vez, houve maior eficácia do contra-ataque nas situações de vitória e empate em relação à derrota $[F(2,20,446)=7,827 ; 0,003 ; \eta 2=0,07]$.

As equipes que venceram os jogos tiveram como média 31,1 $\pm 5,13$ gols por partida sendo 6,09 $\pm 2,92$ gols dos contra-ataques em 7,78 $\pm 3,49$ arremessos realizados com eficácia de $77,60 \pm 18,64 \%$. Os gols de contra-ataque para estas equipes foram responsáveis por $24,90 \pm 10,3 \%$ do total de gols. 


\begin{tabular}{|c|c|c|c|c|c|c|}
\hline & \multicolumn{2}{|c|}{ Vitória } & \multicolumn{2}{|c|}{ Derrota } & \multicolumn{2}{|c|}{ Empate } \\
\hline & Média & $\mathrm{DP}$ & Média & DP & Média & $\mathrm{DP}$ \\
\hline Gols & $31,11^{\mathrm{a}}$ & 5,13 & 24,03 & 4,77 & 26,50 & 2,20 \\
\hline \multicolumn{7}{|l|}{ Contra-ataque } \\
\hline Gols & $6,09^{a}$ & 2,92 & 3,69 & 2,40 & 4,00 & 2,13 \\
\hline Arremessos & $7,78^{\mathrm{a}}$ & 3,49 & 5,34 & 3,00 & 5,12 & 3,31 \\
\hline Eficácia & $77,60^{\mathrm{a}}$ & 18,64 & $65,84^{b}$ & 26,65 & $85,52^{\mathrm{ac}}$ & 16,32 \\
\hline PGCA (\%) & 24,90 & 10,03 & 22,02 & 12,09 & 18,79 & 10,91 \\
\hline
\end{tabular}

$\mathrm{DP}=$ desvio padrão, $\mathrm{PGCA}=$ percentual dos gols de contra-ataque no total de gols. $\mathrm{a}$ ,b e c Diferença significativa $(p<0,05)$ entre vitória, derrota e empate.

Tabela 2. Distribuição do número de gols e eficácia do contra-ataque pelo resultado da partida das equipes participantes do Campeonato Mundial Masculino de Handebol, Suécia 2011.

As equipes derrotadas tiveram como média de gols $24,03 \pm 4,77$ por partida, com 3,69 $\pm 2,40$ gols de contra-ataques dos 5,34 \pm 3 arremessos realizados com eficácia de $65,84 \pm 26,65 \%$. Os gols de contra-ataque foram responsáveis por $22,02 \pm 12,09 \%$ do total de gols das equipes derrotadas.

Nas partidas em que ocorreu empate (4 jogos) as equipes obtiveram como média de gols $26,53 \pm 2,20$, com 4,00 $\pm 2,13$ gols de contra-ataques dos $5,12 \pm$ 3,31 arremessos realizados com eficácia de $85,52 \pm 16,32 \%$. Os gols de contraataque foram responsáveis por $18,79 \pm 10,91 \%$ do total de gols das equipes derrotadas.

\section{DISCUSSÃO}

O presente estudo analisou, a partir dos dados fornecidos pela IHF, arremessos de contra-ataque dos 98 jogos realizados no Campeonato Mundial Masculino de Handebol, Suécia 2011. Nossos resultados apontam que equipes vencedoras 
apresentam maior investimento nas situações de contra-ataques, o que resultou no maior número de ações, gols e eficácia neste quesito em relação às equipes derrotadas.

A análise de arremessos de contra-ataque foi realizada por dois estudos prévios envolvendo os jogos dos Mundiais do Egito de 1999 (GUTIÉRREZ, 1999) e Portugal de 2003 (DE GRUIC, VULETAE MILANOVIC, 2006). No Mundial do Egito de 1999, a média de gols de contra-ataque foi de 7,9, com eficácia de contra-ataque de 75 $\%$, sendo esses gols responsáveis por 18,3\% do total da partida (GUTIÉRREZ, 1999). No Mundial de Portugal de 2003 foram computados 4,19 $\pm 3,21$ gols de contra-ataque, com eficácia de 70,55 \%, correspondendo a $15,46 \%$ dos gols da partida. Embora a média de gols de contra-ataques não tenha aumentado entre os estudos (1999 7,9; $2003 \sim 4,19 ; 2011 \sim 4,85)$, houve incremento da influência desses gols no resultado final da partida chegando a 23,27 $\pm 11,17 \%$ no Mundial de 2011, o que sugere sua crescente importância no desfecho da partida. Nesse sentido, Román (2007) relatou para tendência no aumento da velocidade do jogo e que o jogo em contra-ataque surge mais explorado pelas equipes.

No presente estudo equipes vitoriosas obtiveram número maior de gols de con00tra-ataque e total de arremessos nesta situação em relação as derrotadas. Resultados próximos foram apresentados por Gruic, Vuleta e Milanovic (2006), no qual equipes vitoriosas converteram 5,95 $\pm 3,44$ gols de contra-ataque com $76,86 \%$ de eficácia e equipes derrotadas 2,56 $\pm 2,01$ gols de contra-ataque com $59,35 \%$ de eficácia. Assim, arremessos de contra-ataque parecem discriminar o sucesso ou fracasso entre equipes de handebol masculina de alto nível.

Para os jogos que terminaram empatados apresentaram a maior média de eficácia nos arremessos de contra-ataque 85,52 $\pm 16,32 \%$, embora estatisticamente diferente apenas em relação às equipes derrotadas. $O$ valor chama atenção, pois os 5,12 \pm 3,31 arremessos de contra-ataque realizados resultaram em 4,00 \pm 2,13 gols.. Partidas de equipes com níveis técnicos e táticos diferentes o número de contra-ataques é maior do que nos jogos com participantes de mesmo nível 
(GUTIÉRREZ, 1999) o que reflete no final dos jogos de equipes de mesmo nível e situações de empate.

Este estudo apresenta como limitações a restrição dos dados oficiais divulgados pela IHF, que registra apenas ações ofensivas de contra-ataque finalizadas com arremesso ao gol (resultando em gol ou a defesa do goleiro). Não são divulgadas as ações de contra-ataque que tiveram outra consequência como, por exemplo, o erro de passe, a perda da posse de bola como falhas ofensivas, a penalidade de sete metros devido a falha no balanço defensivo criado por essa situação, ou ainda a participação do goleiro nos lançamentos de contra-ataque. A IHF registra somente o contra-ataque direto e o indireto realizado em forma de câmbio que é finalizado em arremesso.

Rogulj, Srhoj e Srhoj (2004) acrescentam que as melhores equipes usam mais e melhor o contra-ataque direto e sustentado. Sáez, Roldán e Feu (2009) apontam como uma possível causa a postura defensiva que realizam as equipes vitoriosas, que obrigam as equipes derrotadas a realizar arremessos em situações desfavoráveis propiciando falhas que oportunizaram a saída do contra-ataque. Neste sentido podemos inferir que as equipes que foram vitoriosas nas partidas tiveram mais qualidade nesse fundamento, partindo desde a recuperação da bola ou a interferência dos goleiros na fase defensiva a criação da oportunidade de arremesso com o máximo de eficácia, não se precipitando e nem finalizando ao gol em situação desfavorável.

\section{CONSIDERAÇÕES FINAIS}

Equipes vencedoras de handebol masculino de alto nível apresentam maior número e eficácia nas ações de contra-ataque em relação às derrotadas e gols de contra-ataque representam $1 / 4$ do total de gols. $O$ contra-ataque tem se diferenciado entre as equipes vitoriosas e derrotadas tanto no número de gols quanto no total de arremessos nesta situação, e resulta no aumento da velocidade do jogo. Assim, torna-se imperativo para treinadores e atletas a elaboração e 
execução, respectivamente, de treinamentos físicos, técnicos e táticos desta situação de jogo da fase defensiva à eficácia na finalização do arremesso.

\section{REFERÊNCIAS BIBLIOGRÁFICAS:}

ANDAKI JUNIOR, R; SILVA, CE; SALGADO, G.C.; SOUZA, H.B.; SALLES, J.G.C Análise do comportamento defensivo das equipes masculinas finalistas da Liga Petrobrás de handebol 2005. Coleção Pesquisa em Educação Física, 2009, V.8

COHEN J. Statistical power analysis for the behavioral sciences. 2nd ed. Hillsdale: Lawrence Erlbaum, 1988.

DA SILVA, A. B.R.; SOUZA, H. B.; ANDAKI JUNIOR, R.; SILVA, C. E.; SALLES, J. G. C. Análise do contra-ataque das equipes femininas participantes do JIMI 2008. Coleção Pesquisa em Educação Física, 2009, Vol.8, nº1.

DELGADO, MAG. El contragol. Comunicaciones técnicas $n^{\circ} 226$. Área de balonmano, 2004, 14-20.

GARCÍA, JA; ANIZ, I; BARBADO, FD; ARELLANO, JI; NOGALES, JF e BLÁZQUEZ, M. Análisis de los parámetros espaciales en el juego de ataque de los equipos finalistas del Campeonato del Mundo de Balonmano de Portugal. Motricidad. European Journal of Human Movement, 2006, 17, 111-121.

GARCÍA, J. L.A. Balonmano: nuevas aportaciones para el perfeccionamiento y la investigación. Inde, 2000. ISBN 8495114275.

GRUIC, I.; VULETA, D. e MILANOVIC D. Performace Indicators of teams at the 2003 men's world handball Championship in Portugal, Kinesiology, 2006, $38,2: 164-175$ 
GUTIÉRREZ, O. Análisis de las situaciones de contraataque del Mundial Egipto 99. Revista Área de Balonmano, Asociación de Entrenadores de Balonmano, v. 11, 1999.

HERNÁNDEZ, L.M. Análisis praxiológico de la estructura funcional del balonmano. RED - Revista de Entrenamiento Deportivo, 1998, Tomo XII. № 1, pp. 19-27.

RAMíREZ, A.G. Análises praxiológico del contraataque en balonmano. Acciónmotriz, 2010, Revista n5.

ROMÁN, J.D. La Evolución del juego de ataque en balonmano. Revisión Histórica: Los inicios del siglo XXI. E-balonmano.com: Revista Digital Deportiva, 2007, 3(4), 79-99.

ROGULJ, N.; SRHOJ, V.; SRHOJ, L. The contribution of collective attack tactics in differentiating handball score efficiency. Collegium antropologicum, v. 28, n. 2, p. 739-746, 2004. ISSN 0350-6134.

SÁEZ, F.; ROLDÁN, A.; FEU, S. Diferencias en las estadísticas de juego entre los equipos ganadores y perdedores de la copa del rey 2008 de balonmano masculino. E-balonmano. com: Revista de Ciencias del Deporte, v. 5, n. 3, p. 107-114, 2009.

SALLES, J.G.C. Manual: Handebol Fundamentações técnicas, sistemas de jogo e ações táticas iniciais para a equipe. Videocurso Treinamento Técnico e Tático no Handebol. Viçosa: Canal 4 Vídeo Comunicação, 2001. 


\title{
ANALYSIS OF FAST BREAK THROWS IN MEN'S WORLD HANDBALL CHAMPIONSHIP SWEDEN 2011
}

\begin{abstract}
The aim of this study was to determine the number and effectiveness of fast break throws on win, lose or draw match outcome in the World Men's Handball Championship. The sample consisted of 98 games. We analyzed the numbers of fast break goals scored, total number of shots and the effectiveness in this situation. One-way ANOVA followed by Tukey HSB or Welch post hoc tests showed that winning teams had a higher fast break throws number, effectiveness and goals from fast break regarding defeated teams. Goals from fast break are more frequent among winning teams, highlighting its importance tactic for coaches and athletes in their actions for establishing and implementing training.
\end{abstract}

Key words: Handball. Fast break. World championship.

\section{ANALISIS DE LANZAMIENTOS DE CONTRA ATAQUE EN EL CAMPEONATO DE BALONMANO MASCULINO SUECIA 2011}

Resumen: El objeto del estudio fue evaluar el impacto de las acciones lanzamientos contra-ataque, así como la eficiencia de la victoria y derrotó a los equipos en el Campeonato Balonmano Masculino del Mundo. La muestra consistió en 98 partidos. El número de goles de contraataques en total se analizaron parcelas y eficacia en esta situación. El análisis estadístico mostró diferencias significativas $(p<0,001)$ entre el victorioso y derrotó a los equipos en las variables contraatacar objetivos y campos de totales en esta situación. Estos de los goles de contraataques en los partidos con los equipos victoriosos.

Palabras clave: Balonmano. Contraataque. Campeonato del mundo. 